\title{
https://doi.org/10.36470/famen.2020.14c9 \\ PEDAGOGIA SOCIAL: DA INCLUSÃO SOCIAL À ESCOLAR
}

\author{
Edna Oliveira da $\mathrm{Paz}^{1}$
}

\section{RESUMO}

Este trabalho se constitui de uma experiência em educação não formal no contexto de inclusão de educandos com dificuldades de aprendizagem e defasagem escolar. Aqui procuramos contextualizar a pedagogia social e refletir sobre os problemas de aprendizagem que a escola formal não tem conseguido resolver, gerando assim uma busca por espaços não formais que trabalham a aprendizagem com metodologias diferenciadas e devolvendo aos educandos a autoestima perdida e o retorno à escola no enfrentamento das dificuldades de aprendizagens e inclusão dos alunos não alfabetizados na idade certa. A pesquisa apresenta uma abordagem da historicidade da pedagogia social, da educação inclusiva e a defasagem escolar. Constitui-se numa pesquisa de caráter qualitativo, cujos sujeitos são alunos do ensino fundamental. Primeiro aplicou-se um questionário com perguntas abertas e fechadas e a interpretação dos dados foi realizada por meio de uma metodologia de abordagem qualitativa associada à quantitativa. Os resultados sinalizam às realidades encontradas pelos alunos com dificuldades de aprendizagens diante dos diversos desafios que vivenciam no dia a dia.

Palavras-chave: Pedagogia social. Inclusão. Aprendizagens. Educação.

\section{A PEDAGOGIA SOCIAL E EDUCAÇÃO}

Nos cursos de Pedagogia no Brasil, a discussão sobre Pedagogia Social ainda é pouco desenvolvida. Somente há poucas décadas os cursos de pedagogia e as universidades brasileiras começaram a se voltar para o estudo dos segmentos historicamente excluídos. Embora os documentos das Políticas Educacionais brasileiras contemplem a democratização da educação e a qualidade de ensino para todos os cidadãos, ainda existem contradições e distanciamentos significativos entre as leis e as práticas realizadas.

As demandas educacionais e sociais estão exigindo uma nova concepção de educação. Os estudos da Pedagogia apontam essas novas discussões sobre o papel da Educação na formação dos sujeitos historicamente excluídos. Essas discussões nos fazem pensar em uma análise da história do Curso de Pedagogia e das diretrizes, porém em outro momento, já que neste nos deteremos a falar sobre as ações de inserção da Pedagogia Social no curso de Pedagogia.

As Diretrizes Curriculares Nacionais (BRASIL, 2005) trouxeram avanços no que diz respeito às discussões e valorização das minorias excluídas e a defesa dos seus direitos básicos. Esse documento revela que a inclusão desta temática na formação do Pedagogo está propiciando

\footnotetext{
${ }^{1}$ Especialista em Atendimento Especializado Educacional pela Universidade Federal do Ceará - UFC e em Gestão Pública Municipal pela Universidade Federal da Paraíba - UFPB. E-mail: edinha.paz@outlook.com
} 
o respeito a diversidade dos educandos e valorização de suas identidades. Estas questões estão retratadas no próprio documento do Ministério da Educação.

Grande parte dos Cursos de Pedagogia hoje tem como objetivo central à formação de profissionais capazes de exercer a docência na Educação Infantil, nos anos iniciais do ensino Fundamental, nas disciplinas pedagógicas para a formação de professores, assim como para a participação no planejamento, gestão e avaliação de estabelecimentos de ensino, de sistemas educativos escolares, bem como organização e desenvolvimento de programas não-escolares. Os movimentos sociais também têm insistido em demonstrar a existência de uma demanda ainda pouco atendida, no sentido de que os estudantes de Pedagogia sejam também formados para garantir a educação, com vistas à inclusão plena dos segmentos historicamente excluídos dos direitos sociais, culturais, econômicos e políticos (BRASIL, 2005, p.5).

Graciani (2006) afirma que os estudantes de Pedagogia precisam ser formados para garantir a educação, com vistas à inclusão plena dos segmentos historicamente excluídos dos direitos sociais, culturais, econômicos e políticos. Esta concepção de formação do pedagogo voltada para o aspecto social, proporciona os meios necessários para que os sujeitos historicamente excluídos reflitam criticamente sobre o contexto no qual estão inseridos e reivindiquem seus direitos como cidadãos. Nesse sentido, a educação possui um papel fundamental na constituição da sociedade e a Pedagogia é um instrumento significativo na formação e constituição destes sujeitos.

O que observamos é um momento de criatividade pedagógica mais que de sistematização dos conteúdos e dos métodos. Em outras palavras, temos no Brasil educadores que colaboram com o nascimento e o desenvolvimento de uma metodologia com identidade própria, rica de intuição pedagógica e de conteúdo. Ao mesmo tempo nos damos conta de que é chegado o momento no qual precisamos sistematizar toda essa gama de conhecimentos pedagógicos para compreender melhor e interpretar a realidade e projetar intervenções educativas efetivas.

\section{CONTEXTUALIZANDO ALGUMAS DIFICULDADES DE APRENDIZAGEM ESCOLAR}

Segundo Moojen (1999), os problemas na aprendizagem podem ser divididos em duas categorias: os transtornos específicos de aprendizagem (decorrentes do processo de desenvolvimento neurológico) e as dificuldades escolares, que podem estar relacionadas a patologias clínicas, a problemas ambientais e de método de ensino.

A dificuldade específica de aprendizagem caracteriza-se por um funcionamento abaixo do esperado, considerando a idade cronológica e o quociente intelectual do educando, além de, 
interferirem-no rendimento escolar e na vida cotidiana. Para Russo (2015), explicar o mecanismo de aprendizagem é esclarecer a maneira pela qual o ser humano se desenvolve, conhece o mundo em que vive, se organiza e se ajusta ao meio físico e social.

Sobre os requisitos para o diagnóstico citamos dois que Moojen (1999) destaca: a dificuldade de diagnóstico dos transtornos específicos de aprendizagem depende das circunstancias familiares e da escolaridade, bem como das características individuais dos educandos; as dificuldades escolares podem ser decorrentes de problemas sociais, doenças crônicas, distúrbios psiquiátricos, problemas familiares, uso de medicamentos, professores desmotivados e despreparados entre outros.

No atendimento pedagógico, o educador deve ficar atento para os requisitos necessários para a aquisição das novas habilidades, por exemplo, nas dificuldades de aprendizagem de leitura e escrita tem-se que considerar a prontidão para a alfabetização, que significa ter o nível suficiente para iniciar o processo da função simbólica, que é a leitura, e sua transposição gráfica, que é a escrita (MORAIS, 1986). O preparo para iniciar a alfabetização depende da integração dos processos neurológicos e de uma harmoniosa evolução de habilidades como percepção, esquema corporal, lateralidade, entre outros. Para o desenvolvimento da escrita é necessário o desenvolvimento da linguagem oral, das habilidades de orientação espacial e temporal, coordenação visomotora, memória visual e auditiva e motivação para aprender.

Segundo Russo (2015), nas crianças que sofremde discalculia, a capacidade de adquirir as habilidades matemáticas está seriamente prejudicada. Elas não conseguem lidar com o conceito de número, e as situações que envolvem matemática tornam-se um problema na escola e nas atividades cotidianas, porém para compreender os conceitos matemáticos, além dos já citados para a escrita, a criança deve saber seriar, agrupar e representar, aspectos estes negligenciados por muitas escolas.

Para a intervenção dos problemas de aprendizagem, sejam neurológicos, relacionados a patologias, ou formação reativa à escola, faz-se necessário o desenvolvimento psicomotor, observando a evolução normal e os sintomas de distúrbios. Segundo Russo (2015), a educação psicomotora tem por finalidade assegurar o desenvolvimento funcional, observando as possibilidades da criança, e ajudar sua afetividade a se expandir e se equilibrar, por meio do intercâmbio com o meio ambiente. O brincar nesse processo de intervenção é utilizado como forma de explorar as funções cognitivas e de trabalhar aspectos do comportamento afetivo e social da criança. 


\title{
A PEDAgogia SOCIAL E SUA CONTRIBUiÇÃO NA FORMAÇÃo DO(A) PEDAGOGO(A)
}

No percurso de formação e constituição da identidade docente existem inúmeras possibilidades que se apresentam como potencializadoras do trabalho pedagógico, oportunidades que consistem em melhorar e humanizar os processos de ensino-aprendizagem, diante da diversidade de caminhos que existe. A experiência vivenciada, através da prática no âmbito da sala de aula, nos permitiu confrontar as teorias apreendidas na academia e compreender que a prática docente se constitui no âmago da sociedade, na necessidade de ensinar e aprender coletivamente, de fazer-fazendo, na possibilidade dialógica de compreender o outro como parte de nós.

Essa concepção formativa é concebida no processo de formação inicial quando a relação teoria e prática é entendida como oportunidade de aprender junto a sociedade, sendo a teoria a forma como o conhecimento se apresenta e a prática como a materialização dessa teoria em ações concretas, podendo a partir desse diálogo, modificar-se e modificar as teorias (PACHECO; BARBOSA; FERNANDES, 2017). Nesse sentido, a sala de aula proporciona não só uma relação de reflexão e prática, mas também uma atividade de reelaboração, de ressignificação e autoformação, como apontam Nunes e Silva (2011, p. 126),

\begin{abstract}
A relação entre o ensino e a extensão conduz a mudanças no processo pedagógico, pois alunos e professores constituem-se em sujeitos do ato de aprender. Ao mesmo tempo em que a extensão possibilita a democratização do saber acadêmico, através dela, esse saber retorna à universidade testado e reelaborado. A relação entre pesquisa e extensão ocorre quando a produção do conhecimento é capaz de contribuir para a transformação da sociedade. A extensão como via de interação entre universidade e sociedade constitui-se em elemento capaz de operacionalizar a relação entre teoria e prática.
\end{abstract}

A prática de sala de aula, nessa perspectiva, envolve relações sociais e humanas entre professores, estudantes e a comunidade, relações que não sendo neutras, têm objetivos específicos vinculados aos processos de aprendizagem, construindo-os com sentido e contribuindo, assim, para as transformações necessárias (ALMEIDA; SAMPAIO, 2010).

Nessa acepção, é oportuno dizer que as experiências vivenciadas no âmbito da sala de aula, constituíram-se enquanto referências experienciais que possibilita-nos repensar cotidianamente a potencialidade de uma mediação pedagógica comprometida com a transformação social do sujeito e do mundo que o cerca. É gratificante saber que cada minuto dedicado às atividades foi como sementes plantadas em terreno fértil. É por isso que "ensinar exige convicção de que a mudança é possível" (FREIRE, 2017, p. 74), porque de fato é possível, mas para que consigamos transformar 
o mundo do outro, antes é preciso que transformemos o nosso. Refletir metodologicamente e compreender sistematicamente a potencialidade docente nesse processo de intervenção corrobora não só para a constituição de uma identidade pedagógica humanizada, mas também para uma prática socioeducativa significativa.

Neste contexto, a Pedagogia Social aqui vivenciada está compromissada com o desenvolvimento integral tanto do educador quanto do educando, materializando isso diariamente nos encontros. Estar em contato com as crianças semanalmente fez-nos refletir criticamente sobre a qualidade da educação que oportunizamos, as metodologias que podemos praticar, as estratégias que podemos utilizar, tanto para estimular a atenção das crianças quanto para sensibilizá-las sobre a importância de participar das atividades propostas. É por esse aspecto que a extensão pode ser caracterizada como "um processo de aprendizagem vivencial, reflexivo e dialógico, de formação humana, social e profissional" (MENEZES, 2010, p. 14).

O aperfeiçoamento formativo do(a) pedagogo(a) é certamente uma das principais possibilidades que se vislumbra no âmbito da sua prática. Não se trata apenas de ministrar aulas, mas também, a possibilidade de vivenciar as experiências com dedicação, de sentir o abraço de acolhida, de sensibilizar-se a causas nobres, de responder um sorriso com outro sorriso e, acima de tudo, de compreender que sua presença naquele espaço traz alegria e transformação na vida daquelas pessoas. A Pedagogia Social é mais do que um dos espaços para a atuação do(a) pedagogo(a), é a oportunidade de reconhecer a fragilidade do sujeito humano e a possibilidade de abraçá-lo com afetividade.

Essa oportunidade só pode ser proporcionada quando a prática tem o objetivo de transformar, não apenas de investigar, de conhecer, de coletar dados que nem sempre tem retorno devendo ser essencialmente uma possibilidade de inserir-se na sociedade com o objetivo de estabelecer relações concretas, de contribuir para o desenvolvimento, aprimoramento e transformação do espaço no qual se insere os sujeitos (GARCIA, 2012).

Desse modo, a prática possibilita repensar diariamente estratégias de aprendizagens compartilhadas e dialógicas, metodologias que aprimoram sistematicamente a nossa formação enquanto pedagogos(as) e ressignificam os conhecimentos apreendidos no âmbito acadêmico, conduzindo-nos assim, a problematizações que se apresentam como reflexões e oportunidades singulares de qualificar o processo de constituição de uma identidade pedagógica autêntica.

Assim, a Pedagogia Social, aquela que se realiza noutros espaços educativos para além da escola, evidencia um novo caminho pedagógico, uma outra instância de formação e transformação, oportunizando assim, a possibilidade de uma prática humanizadora que se materializa no campo 
social. A atividade desenvolvida concebe em seu âmago o resultado de um trabalho sustentado na dedicação e no esforço coletivo, no sentimento dos sujeitos atendidos, nos depoimentos motivadores que nos direcionam a prosseguir nesse caminho que vai além de um espaço de atuação, que se caracteriza melhor como espaço de transformação.

Transformar é redimensionar uma prática técnica a uma ação humanizadora, é compreender que o pedagogo é um sujeito que necessita e dispõe de ferramenta potencialmente significativa para a formação cidadã.

Permitiram-nos enxergar vivencialmente o que Freire (2006, p. 25) afirma quando escreve "educar e educar-se na prática da liberdade, é tarefa daqueles que sabem que pouco sabem", ou seja, sabendo que pouco sabemos procuraremos saber mais, compreendendo os desafios encontrados como oportunidades autoformativas de crescimento profissional, humano, político e social.

Portanto, as experiências vivenciadas constituem-se como práticas pedagógicas sociais que contribuíram sistematicamente para a formação, profissionalização e progresso dos educandos envolvidos.

\section{CONSIDERAÇÕES FINAIS}

A Educação é um processo que ocorre nos mais diferentes âmbitos da sociedade em se tratando de espaços formais e não formais. Neste sentido, os cursos de Pedagogia e seus formadores precisam estar atentos para formar educadores para atuar nestes vários espaços. Acreditamos que todas as formas de Educação possuem um aspecto relevante, pois, agem perante sujeitos sociais e históricos e fazem parte da constituição dos mesmos. Por isso, faz-se necessário avaliarmos de que forma estas atuações vem ocorrendo nos cursos de Pedagogia e como os pedagogos estão sendo preparados para refletir e atuar na Educação nas suas múltiplas formas de acontecer.

A Pedagogia enquanto instrumento da Educação e a sua dimensão social, precisa ser discutida cotidianamente. O que observamos durante as atividades desenvolvidas é que os alunos que chegam vêm de meios educacionais excludentes, uma escola básica onde o trabalho educativo requer o conhecimento dos diversos aspectos relacionados aos componentes sociais, além dos aspectos cognitivos e aprendizagem escolar. Através das avaliações e intervenções realizadas, podemos localizar e compreender o comportamento dos educandos, interesses, preocupações, conflitos e necessidades. Aspectos estes da organização interna da criança, assim como de sua compreensão do mundo, da vida social e familiar, o que nos possibilitou o reconhecimento de 
problemas e sua possível intervenção. Restando a escola reconhecer esses aspectos e cumprir sua missão educativa e social para com esses educandos.

A intenção deste capítulo foi trazer breves considerações sobre os processos de defasagem ensino-aprendizagem e contextualizá-los à Pedagogia Social, posto que os educandos são de classe desfavorecidas, vivendo de programas sociais, de lares mantidos alguns somente pela mãe, outros pelos avós ou tios, alguns por dependentes químicos, entre outros problemas sociais que de alguma maneira podem ter agravado a situação educacional desses educandos.

Pela análise das atividades e resultados obtidos, vemos que é possível a realização de adequação das atividades escolares, refletindo no aumento da participação dos educandos na escola. Porém, ainda vemos um caminho a trilhar quando a procura por esses espaços cresce a cada dia e o discurso dos que estão na escola são de que estes educandos têm problemas. Na realidade, temos uma escola adoecida que não se reconhece doente, gerando um ciclo de exclusão. Acreditamos que este texto possa contribuir com o despertar de discussões futuras sobre o tema tanto no curso de Pedagogia como nas demais licenciaturas.

\section{REFERÊNCIAS}

ALMEIDA, Luciane Pinho de; SAMPAIO, Jorge Hamilton. Extensão Universitária: aprendizagem para transformações necessárias no mundo da vida. Revista Diálogos: construção conceitual de extensão e outras reflexões significativas. Brasília, n.1, v. 14, dez. 2010. p. 33-41.

BRASIL. Lei de Diretrizes e Bases da Educação Nacional. Lei n. 9.394, 20 de dezembro de 1996.

Parâmetros curriculares nacionais: introdução aos parâmetros curriculares nacionais / Secretaria de Educação Fundamental. - Brasília: MEC/SEF, 1997. 126p.

DAVIS, C.; OLIVEIRA, Z. M. T. Psicologia na Educação. São Paulo; Cortez 1994.

FAGALI, E; VALE, Z. Psicopedagogia Institucional Aplicada: aprendizagem escolar dinâmica e construção na sala de aula. 10. ed. Petrópolis, RJ: Vozes, 2009.

FREIRE, Paulo. Extensão ou comunicação? 13 ${ }^{a}$ ed. São Paulo: Paz e Terra S/A, 2006.

Pedagogia do Oprimido. 64a ed. São Paulo: Paz e Terra, 2017.

Pedagogia da autonomia: saberes necessários à prática educativa. $55^{\mathrm{a}}$ ed. São Paulo:

Paz e Terra, 2017 
GARCIA, Berenice Rocha Zabbot. A contribuição da extensão universitária para a formação docente. 2012. 115f. Tese (Doutorado em Educação - Psicologia da Educação) - Pontifícia Universidade Católica de São Paulo, São Paulo, 2012.

GRACIANI, M.S.S. Pedagogia social: impasses, desafios e perspectivas em construção. In: I Congresso Internacional de Pedagogia Social, 1, 2006, Anais eletrônicos. Faculdade de Educação, Universidade de São Paulo, Disponível em: http://www.proceedings.scielo.br Acesso em: 10 fev. 2020 .

MENEZES. Ana Luisa Teixeira. Extensão: por uma percepção de um conhecimento biocêntrico. Revista Dialogos: construção conceitual de extensão e outras reflexões significativas, Brasília, n. 1. v. 14, dez. 2010. p. 8-15.

MOOJEN, Sonia. Dificuldades ou transtornos de Aprendizagem. In: RUBINSTEIN, Edith. Psicopedagogia: uma prática, diferentes estilos. São Paulo: Casa do Psicólogo. 2012.

MORAIS, A. M. E. Distúrbios de aprendizagem. São Paulo: Edicon, 1986.

NUNES, Ana Lucia de Paula Ferreira; SILVA, Maria Batista da Cruz. A extensão universitária no ensino superior e a sociedade. Mal-Estar e Sociedade, Barbacena, n. 7, v. 4, jul/dez. 2011. p. 119-133. Disponível em: <http://www.uemg.br/openjournal/index.php/malestar/article/view/60/89>. Acesso em: 06 mar. 2020.

PACHECO, Willyan Ramon de Souza.; BARBOSA, João Paulo da Silva.; FERNANDES, Dorgival Gonçalves. A relação teoria e prática no processo de formação docente. Revista de Pesquisa Interdisciplinar, Cajazeiras, n. 2, suplementar, set. 2017. p. 332-340. Disponível em: $<$ http://revistas.ufcg.edu.br/cfp/index.php/pesquisainterdisciplinar/article/view/380>. Acesso em: 06 mar. 2020.

PAIN, Sara. Diagnóstico e tratamento dos problemas de aprendizagem. Porto Alegre. Artmed, 1985.

RUBINSTEIN, Edith. Psicopedagogia: uma prática, diferentes estilos. São Paulo: Casa do Psicólogo. 2012.

RUSSO, Rita Margarida Toller. Neuropsicopedagogia clínica: introdução, conceitos, teoria e prática. Curitiba: Juruá, 2015. 